
\title{
The incorporation of gender perspective into Spanish health
} surveys

\author{
Izabella Rohlfs, Carme Borrell, Lucia Artazcoz, Vicenta Escribà-Agüir
}

J Epidemiol Community Health 2007;61(Suppl II):ii20-ii25. doi: 10.1136/jech.2007.059956

See end of article for authors' affiliations

\section{Correspondence to:}

Dr Izabella Rohlfs,

Universitat de Girona, Departament d'Infermeria, Campus Girona Centre, C/ Emili Grahit, 77, 17002 Girona, Spain; izabella. rohlfs@udg.edu

Accepted 10 July 2007

\begin{abstract}
Background: Most studies into social determinants of health conducted in Spain based on data from health surveys have focused on social class inequalities. This paper aims to review the progressive incorporation of gender perspective and sex differences into health surveys in Spain, and to suggest design, data collection and analytical proposals as well as to make policy proposals.

Methods: Changes introduced into health surveys in Spain since 1995 to incorporate gender perspective are examined, and proposals for the future are made, which would permit the analysis of differences in health between women and men as a result of biology or because of gender inequalities.

Results: The introduction of gender perspective in health surveys requires the incorporation of questions related to family setting and reproductive work, workplace and society in general to detect gender differences and inequalities (for example, domestic work, intimate partner violence, discrimination, contract type or working hours). Health indicators reflecting differential morbidity and taking into account the different lifecycle stages must also be incorporated. Analyses ought to be disaggregated by sex and interpretation of results must consider the complex theoretical frameworks explaining the differences in health between men and women based on sex differences and those related to gender.

Conclusions: Analysis of survey data ought to consider the impact of social, political and cultural constructs of each society. Any significant modification in procedures for collection of data relevant to the study of gender will require systematic coordination between institutions generating the data and researchers who are trained in and sensitive to the topic.
\end{abstract}

$\mathrm{H}$ ealth interview surveys, which provide data about perceived morbidity, lifestyles, living conditions and health service utilisation, as well as revealing attitudes and opinions about specific topics, ${ }^{1}$ are useful in health planning. As such they are recommended by the World Health Organization (WHO) as an efficient way of obtaining population level health information for the improvement of health policy and of providing an evidence based foundation for the monitoring and evaluation of health systems. ${ }^{2}$

However, these surveys suffer from certain limitations. These include the difficulty of making comparisons between different population settings, the analysis of time trends (since many surveys have changed over time, not only in terms of the variables collected but also in the formulation of questions), the difficulty in comparing data collected for the same concepts by different national and international organisations using different scales and the lack of "objective" instruments (that is, from an empirical or biological viewpoint) in order to permit external validation of the data, as most surveys rely on data based on the subjective perceptions of respondents. ${ }^{3}$ Furthermore, surveys frequently ignore social determinants related to the production of health and disease and do not record variables which are required for determining the impact of biological differences and social inequalities that operate differently for men and women. Other health affecting variables or constructs such as social class, gender and work (reproductive and productive) are often not tackled in sufficient depth.

Since considerable theoretical thought has been given to understanding the origins and causes of social inequalities, especially of class and gender inequalities, any study of them in health should take these foundations as a starting point. In the design, statement of questions and data analysis of health interview surveys, the concept of gender perspective gives great importance to those contextual aspects that affect differently or in an unequal manner the health of women and men. Biological factors such as different morbidity must also be taken into consideration as blindness to these can often create inequalities. $^{4}$

Unfortunately, the confusion in the use of the terms "sex" and "gender" is just a sign of several conceptual errors that are frequently made in epidemiological and public health research. The specific case of the erroneous use of the term "gender" would seem to be a misguided belief that political correction requires the use of a synonym for the word "sex". ${ }^{5}$ The term "gender" is also wrongly used to describe or analyse issues or situations which tend to be exclusively related to women.

In addition to biological differences that may determine vulnerability to disease as well as the symptoms and prognosis, women and men differ in their occupational status and in their tasks and assigned responsibilities. The analysis of the influence of these factors on health requires an examination of the deep sexual division both of occupations and of society as a whole that determine the different values, attitudes, expectations and power positions of women and men (gender inequalities) and reveals that gender defines and mediates social relationships between the sexes and, furthermore, that these have an impact on health. ${ }^{6}$

The aim of this paper is to review the progressive incorporation of gender perspective and sex differences into health surveys in Spain and to make proposals for future improvements.

Abbreviations: ENS, Encuesta Nacional de Salud; EOD, experience of
discrimination; SESPAS, Spanish Association of Public Health and Health
Administration 


\section{HEALTH SURVEYS AND THE STUDY OF SOCIAL INEQUALITIES IN HEALTH IN SPAIN}

Health surveys have only been widely used in public health in Spain since the 1980s. The first significant study was conducted in Barcelona in $1983^{7}$ and since then the number of local, regional and national surveys has steadily grown. Almost all the autonomous regions of Spain have now conducted at least one health survey. There have also been seven national health surveys (known in Spanish as Encuesta Nacional de Salud or ENS) conducted in 1987, 1993, 1995, 1997, 2001, 2003 and 2006..$^{8-13}$

To date, the study of social determinants of health using data from surveys has centred on the analysis of associations between socioeconomic level and health indicators. Unlike other routine sources of health information, health surveys collect data that permit factors such as health status, health service utilisation and lifestyles to be compared with demographic variables making it possible to identify the interviewees' socioeconomic status and reveal the gradient of related inequalities and lifestyle and service use patterns. Social class, obtained through occupation, ${ }^{14}{ }^{15}$ and educational level are used as the main variables to study health inequalities in terms of socioeconomic position. However, the incorporation of the study of gender inequalities from health survey data dates back only to the late 1990s and was initially scarce although the study of health gender inequalities in Spain does have a longer history. ${ }^{16}{ }^{17}$ National, regional and local health surveys have progressively begun to incorporate gender perspective into health research.

This greater sensitivity to gender issues and the increase in the number of studies is a result of various factors: (a) international experiences, ${ }^{18-22}$ (b) the exploitation of data from existing surveys, (c) the observation that certain questions formulated to better understand the health of the population and conditioning factors remained unanswered owing to a failure to collect the appropriate explanatory variables, and (d) concerns expressed by advocacy groups which have revealed the need to collect information on emerging and/or little known areas of public health. The first paper to establish the importance of the gender perspective in Spain in all stages of health interview surveys from sample design to question formulation and data analysis was written by the Gender Group of the Spanish Association of Public Health and Health Administration (SESPAS) in 2000. ${ }^{23}$ This influential paper also set the standards for future surveys.

\section{Evolution of gender perspective in national health surveys from 1993-2006}

Table 1 shows clearly how the Spanish national health surveys have evolved since 1993 and includes all the variables that were recommended by the SESPAS Gender Group paper. ${ }^{23}$ As will be observed, the first significant change in the variables was introduced in 2001 and special emphasis was placed in the main ENS report of 2001,11 published by the Ministry of Health

Table 1 Progressive introduction of certain variables, which make it possible to conduct gender perspective analyses, into the Spanish national health surveys (ENS), 1993 to 2005-6

\begin{tabular}{|c|c|c|c|c|c|c|}
\hline & ENS 93 & ENS 95 & ENS 97 & ENS 01 & ENS 03 & ENS 05-6 \\
\hline \multicolumn{7}{|l|}{ Demographic and occupational } \\
\hline De facto marital status & $x$ & $x$ & $x$ & $x$ & $x$ & $x$ \\
\hline Living with a partner & & & & $X$ & $x$ & $x$ \\
\hline Social class & $X^{*}$ & $X^{*}$ & $X^{*}$ & $\mathrm{X} \#$ & X\# & X\# \\
\hline Educational level & $x$ & $x$ & $X$ & $x$ & $\mathrm{x}$ & $x^{\prime \prime}$ \\
\hline Job status & $x$ & $x$ & $x$ & $x$ & $x$ & $x$ \\
\hline \multicolumn{6}{|l|}{ Productive work (paid) } & $x$ \\
\hline Occupation & $x$ & $x$ & $x$ & $x$ & $x$ & $x$ \\
\hline Position & & & & $x$ & $x$ & $x$ \\
\hline Type of firm in which you work or worked ${ }^{* *}$ & & & & $\mathrm{X}$ & $x$ & $x$ \\
\hline \multirow{2}{*}{\multicolumn{7}{|c|}{ Type of contract }} \\
\hline & & & & & & \\
\hline Full time or part time & & & & $\mathrm{X}$ & $x$ & $x$ \\
\hline \multicolumn{7}{|l|}{ Number of hours worked per week } \\
\hline \multicolumn{7}{|l|}{ Reproductive work (unpaid) } \\
\hline Family structure (cohabitation)† & $\mathrm{X}$ & & & $\mathrm{X}$ & $x$ & $x$ \\
\hline Domestic work $\ddagger$ & & & & $\mathrm{X}$ & $x$ & $\mathrm{X}$ \\
\hline Performance of domestic work & & & & $x$ & $x$ & $x$ \\
\hline Sharing of domestic work & & & & $X$ & & $x$ \\
\hline Care of dependent people§ & & & & $\mathrm{X}$ & $X$ - children & $\mathrm{X}$ \\
\hline Sharing of care of dependants & & & & $x$ & $\mathrm{X}$ & $x$ \\
\hline $\begin{array}{l}\text { Availability of outside help (family or contracted) to carry out domestic } \\
\text { and caring work }\end{array}$ & & & & $\mathrm{x}$ & $x$ & $x$ \\
\hline Number of hours of reproductive work & & & & & & $\mathrm{X}$ \\
\hline \multicolumn{7}{|l|}{ Morbidity, perceived health, quality of life and mental health } \\
\hline Perceived health status & $\mathrm{X}$ & $\mathrm{X}$ & $\mathrm{X}$ & $\mathrm{X}$ & $\mathrm{X}$ & $\mathrm{X}$ \\
\hline Mental health and quality of life & & & & & & SF-12 \\
\hline Chronic conditions & $\mathrm{X}$ & $\mathrm{X}$ & $\mathrm{X}$ & $\mathrm{X}$ & $\mathrm{X}$ & $\mathrm{X}$ \\
\hline Number of hours of sleep per day & $\mathrm{X}$ & $\mathrm{X}$ & $\mathrm{X}$ & $\mathrm{X}$ & $\mathrm{X}$ & $\mathrm{X}$ \\
\hline \multicolumn{7}{|l|}{ Social support (existence and type of social network) } \\
\hline \multicolumn{7}{|l|}{ Network structure (size, density) } \\
\hline Functional social support (affective and confidential) & & & & $\mathrm{X}$ & $\mathrm{X}$ & $X$ \\
\hline \multicolumn{7}{|c|}{$\begin{array}{l}\text { *In } 1993,1995 \text { and } 1997 \text { a variable called social status was created: well off; medium-high; medium-medium; medium-low; low. Obtained by crossing leve } \\
\text { education completed (illiterate; finished school aged 14-15 years; finished school aged 16-19 years; additional non-university studies; university studies; unknov } \\
\text { occupation of the head of the household (self employed; public or private sector employee; other) } \\
\text { \#In 2001, } 2003 \text { and } 2005-6 \text { social class was obtained through self occupation. } \\
\text { **Public administration; public or private organisation, non-profit organisation or domestic service. } \\
\text { †Age, sex, relationship of cohabiting individuals. } \\
\text { †Do the shopping, prepare meals, cleaning, ironing, etc. } \\
\text { §Children, elderly, disabled. }\end{array}$} \\
\hline
\end{tabular}


Table 2 Evolution of the list of chronic symptoms or conditions inquired about in the national health surveys (ENS), 1993 to 2005-6

\begin{tabular}{|c|c|}
\hline Survey & Chronic symptoms or conditions \\
\hline ENS 93, 95, 97 & $\begin{array}{l}\text { High blood pressure; raised cholesterol; diabetes; chronic asthma or bronchitis; stomach } \\
\text { ulcer; heart disease; allergies }\end{array}$ \\
\hline ENS 2001 & Added: depression \\
\hline ENS 2003 & $\begin{array}{l}\text { Added: emphysema (with asthma or bronchitis); other mental illness; headaches, } \\
\text { migraines; poor circulation; hernias, arthritis and rheumatic conditions; conditions related } \\
\text { to menopause; conditions related to prostate }\end{array}$ \\
\hline ENS 2005-6 & $\begin{array}{l}\text { Added: myocardial infarction; varicose veins in legs; chronic back pain (neck); chronic } \\
\text { back pain (lumbar); duodenal ulcer (with stomach ulcer); urinary incontinence; cataracts; } \\
\text { chronic skin conditions; chronic constipation; stroke; piles; malignant tumours; anaemia; } \\
\text { thyroid conditions }\end{array}$ \\
\hline
\end{tabular}

and Consumer Affairs, on the new variables that had been introduced with respect to the survey of 1997. The main changes were related to the introduction of variables that would make it possible to obtain a greater understanding of the impact of work, whether paid or domestic, on the health of women and men. Among others variables, interviewees were asked whether they worked full time or part time, how domestic tasks were distributed within the family and who looked after dependent persons in the household.

Early in 2005 a meeting of experts in the design of health surveys, gender perspective and health planning was convened by the Women's Health Observatory of the Spanish Ministry of Health and Consumer Affairs' General Directorate of the National Health Service Quality Agency in order to review the content of previous surveys and elaborate proposals to incorporate gender perspective into the ENS for 2005-6. In addition to variables that had already been included in ENS 2001, the most recent survey has also incorporated items that had been proposed at a later date ${ }^{13}$ and not yet applied, such as the number of hours dedicated to reproductive work (domestic work) and the SF-12 mental health and quality of life questionnaire (see table 1). ENS 2005-6 also included other new variables resulting from changes occurring in society to cover emerging new public health priorities and to generate evidence of social and scientific interest in topics such as discrimination and intimate partner violence that had not been tackled by earlier surveys (see table 3 ).

Table 2 provides examples of the changes that have been introduced over time to the ENS questionnaires in the list of chronic conditions. This is one of the instruments which make it possible to analyse differences in morbidity between women and men in the population as a whole. The inclusion of several additional pathologies in the list may help to throw light on inequalities arising from blindness to biological differences which can have a high impact on quality of life. It has been said that "what is not asked is not known, what is not visible does not exist" ${ }^{24}$ : a clear example of this was seen in the revelation that anaemia is seven times more common in women than in men resulting from the addition of this condition to the list of pathologies in the Health Survey of Catalonia in 2002. ${ }^{25}$

One of the most interesting innovations of the ENS 2005-6 questionnaire was the inclusion of questions adapted from the Stem Experience of Discrimination (EOD) Questionnaire by Krieger et al, ${ }^{26}$ dealing with discrimination in its different forms and settings. Interviewees were asked how they were affected by their sex, educational level, social class, ethnic group or country of origin, sexual preferences and religion when looking for a job, at work, at home (whether by a partner or some other person), in receiving medical care, and in public places. Some variables were also included to determine the nature and the scale of any discrimination that was found.
As we have seen above, health surveys are instruments that need to evolve to encompass new insights into areas of public health concerns and to adapt to social changes. This, however, frequently presents the dilemma as to whether historical series should be maintained in order to allow comparisons between surveys over time.

\section{Analysis with gender perspective}

In spite of the progress achieved in the design of health survey questionnaires in Spain, scientific literature in indexed publications still fails to reflect the significant increase in studies carried out to investigate the impact of gender as a determinant of health in women and men. It should also be noted that many studies and reports offering a gender perspective are not published in scientific journals or by commercial publishers but rather form part of what has been called a "grey literature" that is only made available to a limited readership consisting often only of those who have commissioned the work. Despite the fact that the results of these reports and studies may not be widely or publicly known, it is to be expected that they should act as a foundation for the development of public health policies. ${ }^{27}$

One point that stands out from a review of literature in Spain using the words "gender" or "sex" (1995-2005) $)^{28-47}$ is that although there has been a notable rise in recent years in papers studying the variables mentioned above as being important for determining the impact of gender relationships on health, many do not perform an in-depth study of gender but only conduct a descriptive analysis disaggregated by sex or, alternatively, fit multivariate models adjusted by sex.

Disaggregation by sex, while constituting one of the first steps in any analysis of gender health inequalities, is not sufficient to understand the full underlying complexity of the situation. ${ }^{48}$ The interaction between sex, which unlike gender is a measurable variable, and other variables, social constructs, and biological characteristics can also have an impact on health. These interactions may be additive or multiplicative, and in the multivariate analyses certain factors may counteract the effect of sex. ${ }^{6}$ It should also be noted that the direction of certain associations between variables may be different when the analysis is stratified by sex. Data must be analysed with care in order to emphasise the social relationships between the sexes and clearly delineate underlying inequalities in them. In this respect, one of the aspects to be taken into account in analyses incorporating gender perspective is the life cycle, given that biological and social differences that vary depending on the age group can have a significant impact on determining gender patterns.

\section{PROPOSALS AND CONCLUSIONS}

In a broad definition of health, the analysis of data from vital statistics and health information, principally from surveys, 
Table 3 Some proposals for future national health surveys

\begin{tabular}{|c|c|}
\hline Aspects to take into account & Recommendation \\
\hline Sample & $\begin{array}{l}\text { Bear in mind, when calculating sample size, the subsequent need to disaggregate the } \\
\text { sample by the variables of interest. In order to study social inequalities in health both } \\
\text { sex and socioeconomic level are necessary, and only with a sufficient sample size can } \\
\text { in-depth analyses of these relationships be tackled with the data disaggregated by } \\
\text { these variables, and yet maintaining statistical significance. }\end{array}$ \\
\hline Language used & $\begin{array}{l}\text { Both the language of the interview and that of the instruction manual must take care } \\
\text { that the terms used are not sexist or make one of the sexes invisible, and that there are } \\
\text { no grammatical gender disagreements, nor stereotyped messages. }\end{array}$ \\
\hline \multicolumn{2}{|l|}{$\begin{array}{l}\text { Variables to introduce or go } \\
\text { into in more depth }\end{array}$} \\
\hline Intimate partner violence & $\begin{array}{l}\text { Strict confidentiality and safety must be ensured, and the topic only tackled when the } \\
\text { interviewee is alone. Detailed questions aimed at illuminating gender differences in } \\
\text { patterns, characteristics and risk factors for violence, as well as associated health } \\
\text { problems should be included. Both men and women should be asked these questions } \\
\text { in order to achieve the broadest possible approach to the problem. }\end{array}$ \\
\hline Discrimination & $\begin{array}{l}\text { Expand the questions introduced in ENS 2005-6, according to Stem Experience of } \\
\text { Discrimination (EOD) Questionnaire. }\end{array}$ \\
\hline Social support & $\begin{array}{l}\text { Social support is a possible modulator of the impact on health of negative or stressful } \\
\text { situations. It is important to introduce variables capable of capturing both emotional } \\
\text { and instrumental support. }\end{array}$ \\
\hline Immigration & $\begin{array}{l}\text { Immigration is an issue that has taken on considerable importance in Spain over the } \\
\text { past decade. It is important to study the health of the immigrant population including } \\
\text { questions about country of origin, nationality and years living in Spain along with the } \\
\text { standard variables. }\end{array}$ \\
\hline $\begin{array}{l}\text { Household structure/ } \\
\text { cohabitation }\end{array}$ & $\begin{array}{l}\text { Household structure conditions: aspects such as non-paid workload, overcrowding, } \\
\text { form of cohabitation (single parent family, extended family, various family nuclei, } \\
\text { etc). }\end{array}$ \\
\hline Household work & $\begin{array}{l}\text { Questions that allow determination of the family distribution of domestic tasks and } \\
\text { caring for dependent members; availability of outside (contracted) help in carrying } \\
\text { out domestic tasks; number of household work hours during work days and at the } \\
\text { weekend. }\end{array}$ \\
\hline Job characteristics & $\begin{array}{l}\text { The questionnaire should include questions to permit characterisation of: occupation } \\
\text { of the interviewee and if possible their partner or the person with the highest income } \\
\text { in the household, type of job contract, economic activity and working schedule. }\end{array}$ \\
\hline $\begin{array}{l}\text { Social class and socioeconomic } \\
\text { position }\end{array}$ & $\begin{array}{l}\text { Based on occupation and educational level, the same questions ought to be asked to } \\
\text { determine socioeconomic situation of the partner or other reference person in the } \\
\text { household indicated by the interviewee (the person with highest income). }\end{array}$ \\
\hline Mental health & $\begin{array}{l}\text { It is necessary to include at least one instrument which permits an approach to the } \\
\text { mental health of the population. We recommend Goldberg's questionnaire } \\
\text { (GHQ12). }\end{array}$ \\
\hline Morbidity & $\begin{array}{l}\text { Questions which permit a differential analysis of morbidity by sex and gender. } \\
\text { Morbidity symptoms within a period of two weeks before the date of the interview } \\
\text { would be a helpful measure of self perceived health status. }\end{array}$ \\
\hline Data analysis & $\begin{array}{l}\text { (1) Compare findings of women and men, and supply context in the framework of } \\
\text { social inequalities in health, for which it is not sufficient to simply fit models by sex } \\
\text { (sex as a confounding variable), instead separate analyses should be conducted for } \\
\text { each sex. } \\
\text { (2) Consider relationships and interactions of sex with other contextual variables such } \\
\text { as social class. } \\
\text { (3) Study the diversity of groups of women and compare their health-for example, } \\
\text { in terms of their domestic and paid work loads, presence of social support, or their } \\
\text { having experienced situations of violence or discrimination. } \\
\text { (4) The way results are expressed is also very important, since the aspects that are } \\
\text { emphasised can condition the interpretation that is made. }\end{array}$ \\
\hline
\end{tabular}

needs to consider the impact of the social, political and cultural constructs of each society. ${ }^{49}$ For example, as stated before, collecting data on working conditions inside and outside the household is fundamental to understand health outcomes of women and men.

As is detailed in table 3, careful attention to certain aspects of survey design, incorporating a gender perspective into health surveys, and to the correct analysis of the data and the way that it is expressed is essential in order to deepen our understanding of public health inequalities. ${ }^{6} 2648$ 50-52

The researcher in public health must be aware that there are informational gaps; that it is often impossible to disaggregate data by sex, although it should be borne in mind, as mentioned earlier, that an analysis disaggregated by sex is not sufficient to understand the importance of gender as a determinant of health in women and men. In any case, a critical reading of the findings, which must be discussed within the historical, political and social contextual framework of the society in which men and women live, is absolutely essential.

While improvements and innovations to surveys are often the result of scientific evidence, they may also be introduced in response to the work of advocacy groups, which have revealed the need to collect information on emerging issues, or issues that are not sufficiently studied from a public health perspective. ${ }^{53}$ The inclusion of gender perspective in health surveys is an example of modification being made as a result of a combination of both of these reasons.

That there is growing scientific interest and political will regarding the study of gender inequalities in health can be clearly observed. Health surveys in general, and in the case of Spain the ENS, are excellent sources of information for determining these inequalities, and their use not only for research but also for health planning and the formulation of public policy should be actively encouraged. 


\section{What this paper adds}

- It was found that health surveys often fail to take into account the social determinants related to the production of health and disease. Aspects such as social class, gender and work (reproductive and productive), which affect people's health, are often not tackled in sufficient depth.

- Furthermore, the variables required to determine the impact of biological differences and social inequalities which operate differently for men and for women are frequently not collected.

- The paper reviews the progressive incorporation of gender perspective into health surveys in Spain and makes proposals for future improvements.

\section{Policy implications}

- Taking a broad definition of health, the analysis of data from health surveys ought to consider the impact of social, political and cultural constructs of the population being studied.

- In refining the design of populational health surveys, it is essential that policymakers, social health investigators, epidemiologists and interest groups should contrast their perspectives and pool their knowledge in order to establish national guidelines that overcome shortcomings in the identification of gender and other social inequalities, which result in the failure to address unseen needs.

- The improved resulting data will help in formulating action plans that equitably tackle disadvantaged sectors of society.

\section{ACKNOWLEDGEMENTS}

We thank Maria Frigola Campasol for her helpful revision of Spanish Health Interview Survey Questionnaires, Alicia Baltasar, GREGIS (Girona's Research Group in Gender and Health), for her support and suggestions, and all the participants in the meeting of experts in health survey design, gender perspective and health planning held in 2005 at the Women's Health Observatory of the Ministry of Health and Consumer Affairs' General Directorate of the National Health Service Quality Agency, Spain.

\section{Authors' affiliations}

Izabella Rohlfs, Carme Borrell, Lucia Artazcoz, Vicenta Escribà-Agüir, Gender and Health Research Network (RISG)

Izabella Rohlfs, University of Girona, Girona, Spain

Carme Borrell, Lucia Artazcoz, Agència de Salut Pública, Barcelona, and Epidemiology and Public Health Centres Network, Spain Izabella Rohlfs, Carme Borrell, Lucia Artazcoz, Vicenta Escribà-Agüir, CIBER Epidemiología y Salud Pública (CIBER ESP), Spain

Carme Borrell, Pompeu Fabra University, Barcelona, Spain Vicenta Escribà-Agüir, Valencian School for Health Studies (EVES). Generalitat Valenciana, Valencia, Spain

\section{REFERENCES}

Sawick F. Interview surveys for decision makers. In: McLachlan G, eds. Information Systems for Health Services. Copenhagen: WHO, 1980:73-85.

2 World Health Organization. World health surveys. Geneva: WHO, 2003, [Accessed 5 May 2006] Available at http://www.who.int/healthinfo/survey/ en/index.html.
3 Sadana R, Mathers $C D$, López $A D$, et al. Comparative analyses of more than 50

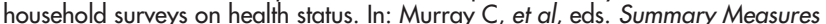
of Population Health: concepts, ethics, measurement and applications. Geneva: WHO, 2002:369-86.

4 Ostlin P, Danielsson M, Diderichsen F, et al, eds. Gender inequalities in health. a Swedish perspective. Boston: Harvard Center for Population and Development Studies, 2001

5 Udry JR. The nature of gender. Demography 1994;31:561-73.

6 Krieger N. Genders, sexes, and health: what are the connections-and why does it matter? Int J Epidemiol 2003;32:652-7

7 Antó JM, Company A, Domingo A. Enquesta de Salut a Barcelona. In: Subàrea de Salut Pública, eds. Sèrie Salut Pública 2. Barcelona: Ajuntament de Barcelona, 1984.

8 Biglino L, Coronado A, Gil E, et al. Encuesta Nacional de Salud. Rev San Hig Pub 1994:68:121-78.

9 Subdirección General de Epidemiología, Promoción y Educación para la Salud. Encuesta Nacional de Salud. Encuesta Nacional de Salud de España, 1995. Madrid: Ministerio de Sanidad y Consumo).

10 Subdirección General de Epidemiología, Promoción y Educación para la Salud. Encuesta Nacional de Salud. Encuesta Nacional de Salud de España, 1997. Madrid: Ministerio de Sanidad y Consumo).

11 Subdirección General de Epidemiología, Promoción y Educación para la Salud. Encuesta Nacional de Salud. Encuesta Nacional de Salud de España, 2001. Madrid: Ministerio de Sanidad y Consumo).

12 Subdirección General de Epidemiología, Promoción y Educación para la Salud. Encuesta Nacional de Salud. Encuesta Nacional de Salud de España, 2003. Madrid: Ministerio de Sanidad y Consumo).

13 Subdirección General de Epidemiología, Promoción y Educación para la Salud. Encuesta Nacional de Salud. Encuesta Nacional de Salud de España, 2005. Madrid: Ministerio de Sanidad y Consumo).

14 Domingo A, Marcos J. Propuesta de un indicador de la clase social basado en la ocupación. Gac Sanit 1989;3:320-26.

15 Grupo de trabajo de la SEE y de la SEMFyC. Una propuesta de medida de la clase social. Aten Primaria 2000;25:350-63.

16 Ruiz MT, Verbrugge LM. A two way view of gender bias in medicine. J Epidemiol Community Health 1997;51:106-9.

17 Dean K, Colomer C, Perez-Hoyos S. Research on lifestyles and health: searching for meaning. Soc Sci Med 1995;41:845-55.

18 Arber S. Class, paid employment and family roles: making sense of structural disadvantage, gender and health status. Soc Sci Med 1991;32:425-36.

19 Roos E, Burstrom B, Saastamoinen P, et al. A comparative study of the patterning of women's health by family status and employment status in Finland and Sweden. Soc Sci Med 2005;60:2443-51

20 Lahelma E, Arber S, Kivela K, et al. Multiple roles and health among British and Finnish women: the influence of socioeconomic circumstances. Soc Sci Med 2002;54:727-40

21 Whitehead M, Burstrom B, Diderichsen F. Social policies and the pathways to inequalities in health: a comparative analysis of lone mothers in Britain and Sweden. Soc Sci Med 2000;50:255-70.

22 Stafford M, Cummins S, Macintyre S, et al. Gender differences in the associations between health and neighbourhood environment. Soc Sci Med 2005;60:1681-92.

23 Rohlfs I, Borrel C, Anitua C, et al. La importancia de la perspectiva de género en las encuestas de salud. Gac Sanit 2000;14:146-55.

24 Rohlfs I, Valls-Llobet C, Pérez G. Les desigualtats de gènere en la salud. In: Borrell C, Benach J, eds. Evolució de les desigualtats en la salud a Catalunya, Barcelona Fundació Jaume Bofill - CAPS.Editorial Mediterrània, 2005:162-201.

25 Generalitat de Catalunya. Departament de Sanitat i Seguretat Social. Enquesta de salut de Catalunya 2002. Barcelona: Departament de Sanitat i Seguretat Social, 2003

26 Krieger N, Smith K, Naishadham D, et al. Experiences of discrimination: validity and reliability of self-report measure for population health research on racism and health. Soc Sci Med 2005;61:1576-96.

27 Gray BH. Sources used in health policy research and implications for information retrieval systems. J Urban Health 1998;75:842-52.

28 Rohlfs I, de Andrés J, Artazcoz L, et al. Influencia del trabajo remunerado en el estado de salud percibido de las mujeres. Med Clin (Barc) 1997; 108:566-71.

29 Fernández E, Schiaffino A, Rajmil L, et al. Gender inequalities in health care services use in Catalonia (Spain). J Epidemiol Community Health 1999;53:218-22.

30 Borrell C, Rue M, Pasarin MI, et al. Trends in social class inequalities in health status, health-related behaviors, and health services utilization in a southern European urban area (1983-1994). Prev Med 2000;31:691-701.

31 Borrell C, Domínguez-Berjón F, Pasarín MI, et al. Social inequalities in health related behavious in Barcelona. J Epidemiol Community Health 2000 :54:24-30.

32 Fernández E, Schiaffino A, Rajmil L, et al. Desigualdades en salud según la clase social en Catalunya 1994. Aten Primaria 2000;25:96-102.

33 Fernández, Schiaffino A, Martí M. Influencia del trabajo doméstico sobre la salud y la utilización de servicios sanitarios en mujeres con trabajo remunerado y amas de casa. Gac Sanit 2000;14:287-90.

34 Artazcoz L, Borrel C, Rohlfs I, et al. Trabajo doméstico, género y salud en población ocupada. Gac Sanit 2001;15:150-3.

35 Artazcoz L, Borrell C, Benach J. Gender inequalities in health among workers: the relation with family demands. J Epidemiol Community Health 2001:55:639-47.

36 Borrell C, Fernández E, Schiaffino A, et al. Social class inequalities in the use of and acces to health services in Catalonia, Spain: what is the influence of supplemental private health insurance? Int J Qual Health Care 2001 ; 13:1 17-25. 
37 Fernández E, Garcia M, Schiaffino A, et al. Smoking initation and cessation by gender and educational level in Catalonia, Spain. Prev Med 2001;32:218-23.

38 Coma A, Martí M, Fernández E. Educación y clase social basada en la ocupación: su interrelación como indicadores de posición socioeconómica en el estudio de las desigualdades sociales mediante encuestas de salud. Aten Primaria 2003;32:208-15.

39 Artazcoz L, Benach J, Borrell C, et al. Unemployment and mental health: understanding the interactions among gender, family roles, and social class. Am J Public Health 2004;94:82-8.

40 Artazcoz L, Borrell C, Benach J, et al. Women, family demands and health: the importance of employment status and socio-economic position. Soc Sci Med 2004;59:263-74.

41 Artazcoz L, Moya C, Vanaclocha H, et al. La salud de las personas adultas. Gac Sanit 2004;18(Suppl 1):56-68.

42 Borrell C, Muntaner C, Benach J, et al. Social class and self-reported health status among men and women; what is the role of work organisation, household material standards and household labour? Soc Sci Med 2004;58:1869-87.

43 Cortes I, Artazcoz L, Rodriguez-Sanz M, et al. Desigualdades en la salud mental de la población ocupada. Gac Sanit 2004;18:351-9.
44 Dominguez-Berion MF, Borrell C, Pastor V. Indicadores socioeconómicos de área pequeña en el estudio de las desigualdades en salud. Gac Sanit 2004;18:92-100.

45 Gonzalo E, Pasarín MI. La Salud de las personas mayores. Gac Sanit 2004;18(Suppl 1):69-80.

46 Rius C, Fernández E, Schiaffino A, et al. Self perceived health and smoking in adolescents. J Epidemiol Community Health 2004:58:698-9.

47 Artazacoz L, Benach J, Borrell C, et al. Social inequalities in the impact of flexible employment on different domains of psychosocial health. J Epidemiol Community Health 2005;59:761-7.

48 Kunkel SR, Atchley RC. Why gender matters: being female is not the same as not being male. Am J Prev Med 1996; 12:294-6.

49 Rohlfs I, Borrell C, do C Fonseca M. Género, desigualdades y salud pública: conocimientos y desconocimientos. Gac Sanit 2000;14(Suppl 3):60-71.

50 Ellsberg $M$, Heise L, Pena R, et al. Researching domestic violence against women: methodological and ethical considerations. Stud Fam Plann 2001;32:1-16.

51 Goldberg DP, Williams P. A user's guide to the general health questionnaire. Windsor: NFER-Nelson, 1978:1-32.

52 Eichler M. Feminist methodology. Curr Sociol 1997;45:9-36.

53 Krieger N. Questioning epidemiology: objectivity, advocacy, and socially responsible science. Am J Public Health 1999;89:1151-3.

\section{APHORISM OF THE MONTH}

"I believe that women-centred, physiologically accurate knowledge of what is normal related to our female bodies, menopause, menstrual cycles and many other aspects of our health does not exist" Jerilynn C Prior

$\int$ erilynn Prior made this statement during the First Congress on Women, Health, and Work (Barcelona, 1996). She is one of the first researchers who, over 20 years ago, realised that to avoid perceiving women as victims of their bodies or their culture an alternative approach was necessary. She thought it necessary to studying their health while taking biological, psychological and sociocultural factors into account. She also realised that this approach required taking what was "normal" in women's biology as a starting point. When early in her career Jerilynn Prior had begun researching the role of the healthy menstrual cycle in the entire body's functions, both during the reproductive period and during the transition towards menopause, she assumed that this "normalcy" was already defined in science, even if it was ignored or not applied. However, what she discovered was that this basic, necessary information simply did not exist. She has been devoted to this task ever since. ${ }^{1-5}$

Correspondence to: Dr Margarita López-Carrillo, CAPS, París, 150 1r 2a Barcelona 08036, Spain; redcaps@pangea.org

\section{REFERENCES}

1 Prior JC, Vigna Y. Conditioning exercise and premenstrual symptoms. J Reprod Med 1987;32:423-8.

2 Prior JC, Vigna YM, Schulzer M, et al. Determination of luteal phase length by quantitative basal temperature methods: validation against the midcycle LH peak. Clin Invest Med 1990;13:123-31.

3 Prior JC, Vigna YM, Schechter MT, et al. Spinal bone loss and ovulatory disturbances. N Engl J Med 1990;323:1221-7, Erratum in: N Engl J Med, 1993;328:1724.

4 Prior JC. The ageing female reproductive axis II: ovulatory changes with perimenopause. Novartis Found Symp 2002;242:172-86.

5 Prior JC. Ovarian aging and the perimenopausal transition: the paradox of endogenous ovarian hyperstimulation. Endocrine 2005;26:297-300 